\title{
Exploratory Dielectric Study involving Ultra-low Content of Si-C-Al in Epoxy
}

\author{
M. F. Fréchette ${ }^{1}$, I. Preda ${ }^{1,2}$, H. Alamdari ${ }^{3}$, P. Lewin ${ }^{4}$, A. Holt ${ }^{4}$, T. Heid ${ }^{1,2}$ \\ ${ }^{1}$ Institut de recherche d'Hydro-Québec (IREQ), QC, Canada \\ ${ }^{2}$ Ecole de Technologie Supérieure (ETS), QC, Canada \\ ${ }^{3}$ Université Laval, Québec (UL), QC, Canada \\ ${ }^{4}$ University of Southampton (SOTON), United Kingdom
}

\begin{abstract}
Ball milling was used to prepare a mixture of Silicon, Graphite and Aluminum, in equal proportion. X-ray analysis (XRD) confirmed that $\mathrm{SiC}$ was not produced in the present milling conditions. Aluminum was identified as being partially oxidized. The powder microstructure was found to be rather micrometric in size. Epoxy samples were casted using the Si-C-Al powder as an additive. Neat epoxy and a composite containing $0.1 \mathrm{wt} \%$ of the filler were prepared. A series of dielectric tests were performed in order to compare the behavior of neat and composite epoxy. Dielectric responses at $20^{\circ} \mathrm{C}$ were found to be very similar, whether the excitation field was low or high. However, erosion experiments have allowed to discriminate the performance of the samples, with a definite worsened resistance to discharges from the composite sample.
\end{abstract}

\section{INTRODUCTION}

After a first generation of nanodielectrics emerging over the last decade, new innovative ways are being explored to tailor the dielectric properties of the polymer nanocomposites or hybrid composites. This work is concerned with an unusual additive with the aim of affecting the functionality of the epoxy.

Silicon (Si), Graphite (C) and Aluminum (Al) were milled together following three different recipes. X-rays analysis (XRD) was used to detect if Silicon Carbide ( $\mathrm{SiC}$ ) was produced or not in the present conditions and if the $\mathrm{Al}$ was partially oxidized or not. Electronic microscopy was employed to image the powder microstructure. Thus, some efforts had to be devoted to establish the nature and characteristics of our additive.

Epoxy samples were casted using the $\mathrm{Si}-\mathrm{C}-\mathrm{Al}$ powder as an additive. Epoxy was DER and a composite containing $0.1 \mathrm{wt} \%$ of the filler was prepared. The use of an ultra-low content warranted a reasonable filler distribution and a condition of no sedimentation. The resulting sample was observed using optical microscopy and SEM. Thermal diffusivity and the glass transition temperature were determined for neat and composite epoxy, showing great similarities in value.

After a post-heat treatment of the samples, a series of dielectric tests were performed in order to compare the behavior of neat and composite epoxy. For instance, dielectric responses at $20^{\circ} \mathrm{C}$ were found to be, respectively, very similar. However, an erosion experiment has allowed discrimination between the performance of the samples, with a definite worsened resistance to discharges from the composite sample. Although preliminary in nature, this observation would tend to

indicate that this adjunct brings about more defects, a situation more dominant than the one associated with the corresponding low-degree of self-assembly of the composite. There is also the role of free carbon to be concerned about.

\section{MATERIALS, SAMPLE PREPARATION AND EXPERIMENTAL METHODS}

High energy ball milling was used to prepare a mixture of Silicon (Si), Graphite (C) and Aluminum (Al). Each component was added to a crucible in equal proportion $(1: 1: 1$ atomic ratio), totaling about $2 \mathrm{~g}$. The high energy impact grinder using tempered steel balls was operated during $3 \mathrm{~h}$, following three different recipes:

1. the mixture was ball-milled for $3 \mathrm{~h}$ at room temperature;

2. the mixed powder was heat-treated at $500{ }^{\circ} \mathrm{C}$ during $2 \mathrm{~h}$ and then, the mixture was ball-milled for $3 \mathrm{~h}$ in air at room temperature;

3. the mixed powder was heat-treated at $1000{ }^{\circ} \mathrm{C}$ during $2 \mathrm{~h}$ and then, the mixture was ball-milled for $3 \mathrm{~h}$ in air at room temperature.

Given in Fig. 1, a micrograph obtained using SEM shows the microstructure of the mixture treated at $500^{\circ} \mathrm{C}$ and ballmilled for $3 \mathrm{~h}$. The corresponding chemical composition of the emphasized spot (labeled Spectrum 1), obtained by Energydispersive X-Ray spectroscopy (EDX), is also shown in Fig. 1.
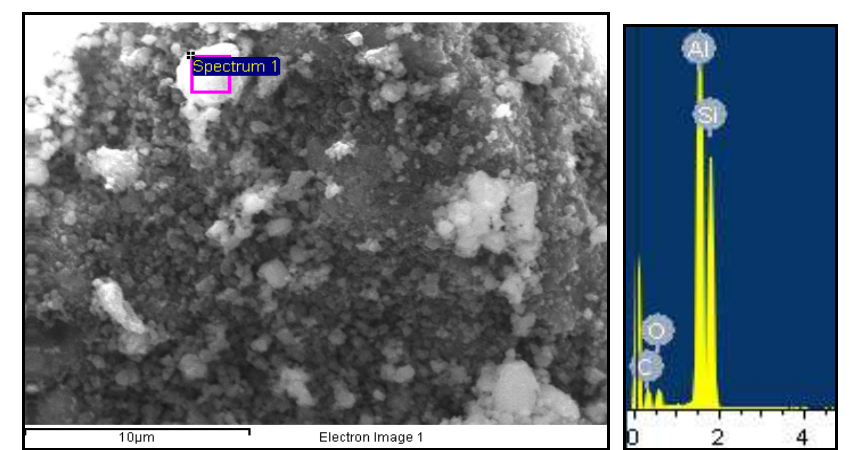

Figure 1. Scanning Electron Microscopy image of the powder obtained using recipe 2 , as well as the corresponding chemical composition of the emphasized spot (obtained by Energy-dispersive X-Ray spectroscopy) 


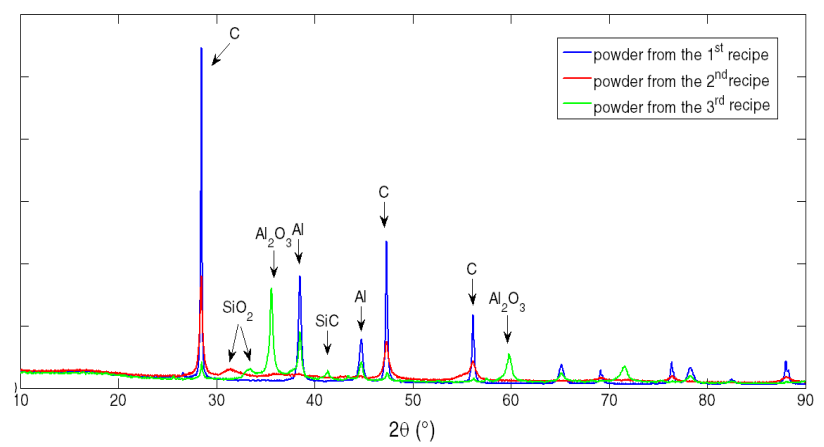

Figure 2. X-Ray Diffraction results obtained for the three types of powders

From the SEM imagery, the powder grain size was found to be inferior to $10 \mu \mathrm{m}$. The EDX results confirmed the expected composition of the powder since Aluminum, Carbon and Silicon were detected. Even more, the presence of oxygen suggests that part of the powder could have been oxidized during the ball-milling procedure and thus, secondary reaction components, such as alumina $\left(\mathrm{Al}_{2} \mathrm{O}_{3}\right)$ were possibly obtained.

To verify this hypothesis, X-Ray Diffraction (XRD) measurements were performed in a Bragg-Brentano geometry and the powders obtained from the three recipes were characterized. The diffraction angle $2 \theta$ was measured between 10 and $90^{\circ}$ using an X-ray source with a copper anode, with a wavelength $\lambda=1.5418 \AA$. The obtained results are presented in Figure 2. A tentative identification of the obtained diffraction peaks was performed using data found in the literature [1-3]. As shown, the obtained results confirm that $\mathrm{SiC}$ was not produced in the present conditions and that the Aluminum was partially oxidized, as suggested by the EDX results. This is a consequence of the powder preparation in atmospheric conditions. A possible solution to remedy this would be using high energy milling under controlled atmosphere, like argon [4]. Also, when a thermal treatment was used during preparation $\left(2^{\text {nd }}\right.$ and $3^{\text {rd }}$ recipe $)$, silica $\left(\mathrm{SiO}_{2}\right)$ was possibly obtained as a consequence of the oxidation of Silicon. This occurs at high temperature under oxidative atmosphere.

The powder obtained from the $2^{\text {nd }}$ recipe was selected in order to prepare an epoxy resin composite. For this, DER332 epoxy resin was mixed with Jeffamine D230 hardener in a 1000:344 ratio. Both the resin and the hardener were degassed individually for 15 minutes at $40{ }^{\circ} \mathrm{C}$. Before degassing the hardener, $0.1 \mathrm{wt} \%$ of filler was added and the hardener-filler mixture was sonicated in an ultrasonic bath for 30 minutes, to separate the agglomerated powder and also to obtain a better distribution of the filler within the epoxy matrix. Afterwards, both the epoxy and the hardener-filler mixture were mixed with a magnetic stirrer, and degassed for further 15 minutes, at $40{ }^{\circ} \mathrm{C}$. Finally, the mixture was poured into stainless steel moulds with an $1 \mathrm{~mm}$ spacer (previously treated with a release agent) and cured at $100{ }^{\circ} \mathrm{C}$, for 6 hours. The same procedure was applied in order to prepare a neat epoxy sample.

Given that the size of the powder grains were in the micrometric range, the dispersion of the filler into the epoxy matrix was investigated using an optical microscope and the obtained results are presented in Figure 3.
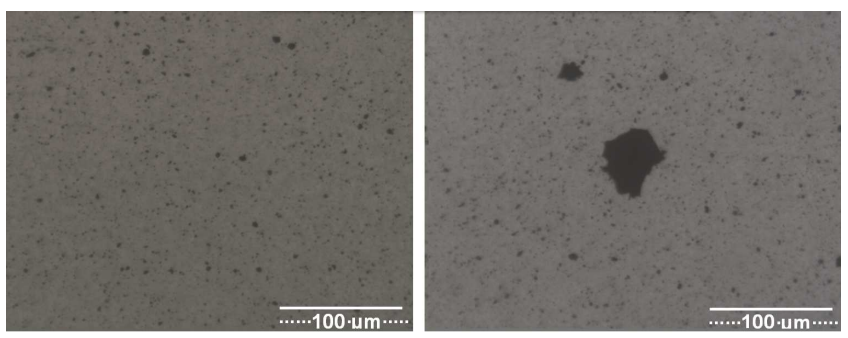

Figure 3. Imaging of the epoxy/Si-C-Al composite using optical microscopy

As shown in Figure 3, the powder had a general good dispersion, although agglomerations of about $70 \mu \mathrm{m}$ were also found. Despite these agglomerations, the distribution of the particles was considered satisfactory and the sample was considered as quasi-homogenous. Consequently, the thermal and dielectric investigation of the neat and composite epoxy were performed.

First, the thermal stability was investigated using Thermogravimetric Analysis (TGA) and Differential Scanning Calorimetry (DSC). TGA was performed under nitrogen, going from $50{ }^{\circ} \mathrm{C}$ to $600{ }^{\circ} \mathrm{C}$, with a $10{ }^{\circ} \mathrm{C} / \mathrm{min}$ increase in temperature. The DSC measurements were conducted under nitrogen atmosphere, using the same heating rate, from $-50{ }^{\circ} \mathrm{C}$ to $200{ }^{\circ} \mathrm{C}$. The first heating procedure was followed by a cooling step, down to $-50{ }^{\circ} \mathrm{C}$, at the same speed, and by a second heating procedure up to $200{ }^{\circ} \mathrm{C}$. The obtained TGA results were extremely similar, which suggested that the thermal properties of the epoxy were not affected by the presence of Si-C-Al additive. Thus, only the results obtained from the DSC investigation are given in the results section.

Secondly, Thermal Diffusivity tests were performed using the flash method. For all measurements, the width of the light pulse was of $0.18 \mathrm{~ms}$ and it was applied on disc-shaped samples of about $10 \mathrm{~mm}$ in diameter, at room temperature. Five consecutive tests were performed for each investigated sample and their mean was considered as the final characteristic value.

To continue, both materials were exposed to partial discharges (PD). The applied voltage was $20 \mathrm{kV}$ peak-to-peak, at $300 \mathrm{~Hz}$, in air. The measurement was stopped after 24 hours due to the breakdown of the composite sample. Despite the breakdown, the erosion progression could still be evaluated using a Dektak mechanical profilometer and the values of total eroded volume were obtained. The experimental setup and the evaluation procedure used were described in [5].

To conclude the study, the dielectric response of the neat and composite epoxy was investigated at room temperature, under both low and high electric field. But, before performing this step, a 24-h long post-thermal treatment was performed at $100{ }^{\circ} \mathrm{C}$. After performing this thermal treatment, all the samples were considered to be in a stable but aged dielectric state [6]. Afterwards, the real and imaginary parts of the complex dielectric permittivity were obtained from $0.1 \mathrm{~Hz}$ to $10^{4} \mathrm{~Hz}$. First, a sinusoidal voltage of $1 \mathrm{~V}_{\text {rms }}$ was applied, followed by $100 \mathrm{~V}, 500 \mathrm{~V}$ and, finally, $1 \mathrm{kV}$. The meas- 


\section{RESULTS AND DISCUSSION}

TABLE I

Glass Transition, Thermal Diffusivity and Partial Discharge Results

\begin{tabular}{|c|c|c|c|}
\hline Sample & $\begin{array}{c}\text { Glass } \\
\text { transition }\left({ }^{\circ} \mathbf{C}\right)\end{array}$ & $\mathbf{D}\left(\mathbf{m m}^{2} / \mathbf{s}\right)$ & $\begin{array}{c}\text { Total eroded } \\
\text { volume }\left(\boldsymbol{\mu m}^{\mathbf{3}}\right)\end{array}$ \\
\hline Neat Epoxy & 79 & $0.11 \pm 0.01$ & $3.12 \cdot 10^{9}$ \\
\hline $\begin{array}{c}\text { Epoxy/Si-C-Al } \\
\text { composite }\end{array}$ & 81 & $0.12 \pm 0.01$ & $2.52 \cdot 10^{11}$ \\
\hline
\end{tabular}
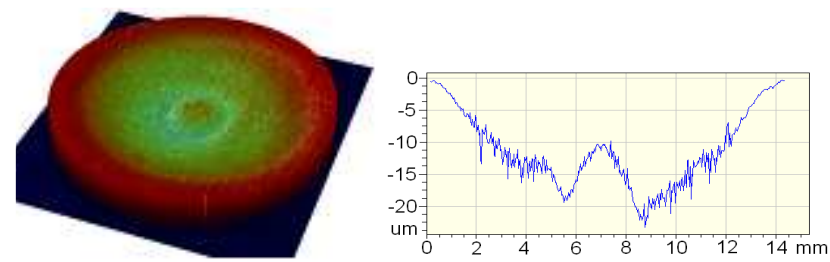

Figure 4. 3D plot of the eroded volume obtained for the neat epoxy and the 2D surface roughness profile through the center of the investigated surface

urements were performed using a parallel plate configuration and the average value of 10 consecutive measurements was considered for each point.

Table I summarizes the values obtained after performing glass transition, thermal diffusivity and partial discharge measurements. On one hand, we can observe that the neat and the composite materials exhibit very similar glass transition temperatures, close to those published for composites obtained using the same resin-hardener mixture, yet with silica or boron nitride nanofillers [7]. The thermal diffusivity values were also close, which is not a surprising result given the low amount of powder that was used for the composite material (0.1 wt $\%)$. On the other hand, as mentioned previously, the erosion experiment has shown an interesting contrast between the two investigated materials. The composite material was found to be less resistant to surface partial discharge and it suffered a breakdown after a 24-hour exposure. By comparing the total eroded volume, it can be seen that a significant difference was obtained between investigated materials. The composite sample had a total eroded volume two decades higher than the neat epoxy, which corresponds to a partial discharge resistance two decades higher for the neat material than for the epoxy/Si$\mathrm{C}$-Al composite. The 3D plot of the eroded surface of the neat epoxy is given in Fig. 4, as well as the 2D surface roughness

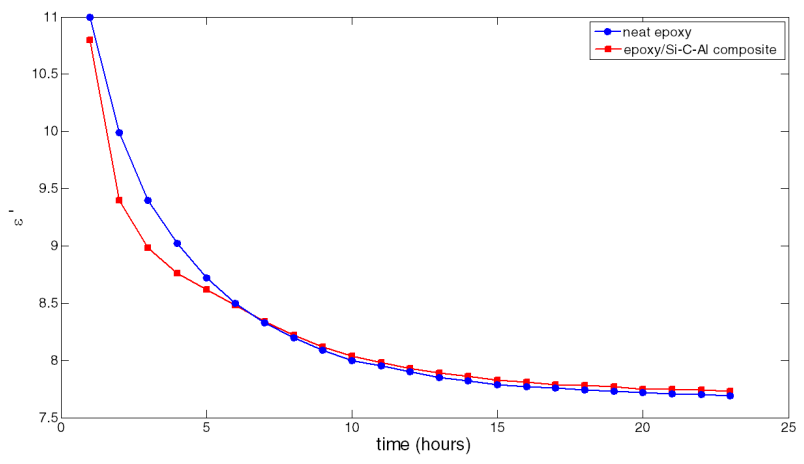

Figure 5. The evolution of the real permittivity for the neat epoxy during the post heat treatment at $0.1 \mathrm{~Hz}$

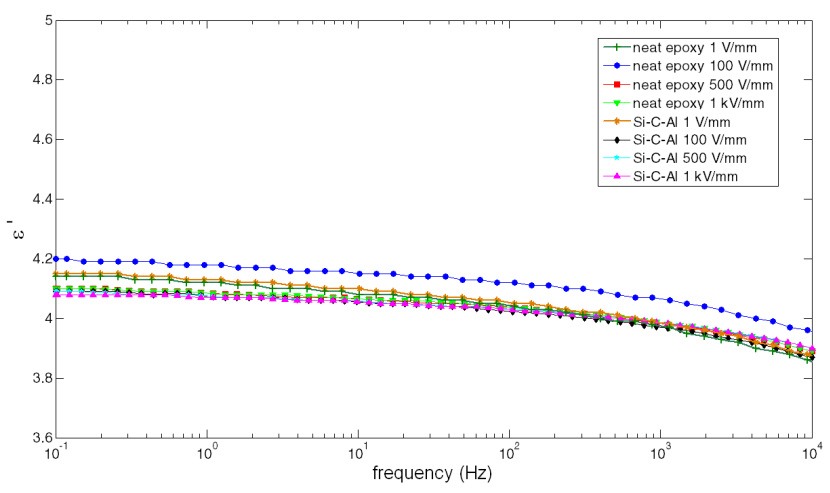

Figure 6. Real permittivity under low and high electric field (from $1 \mathrm{~V} / \mathrm{mm}$ to $1 \mathrm{kV} / \mathrm{mm}$ ), for both neat and composite sample

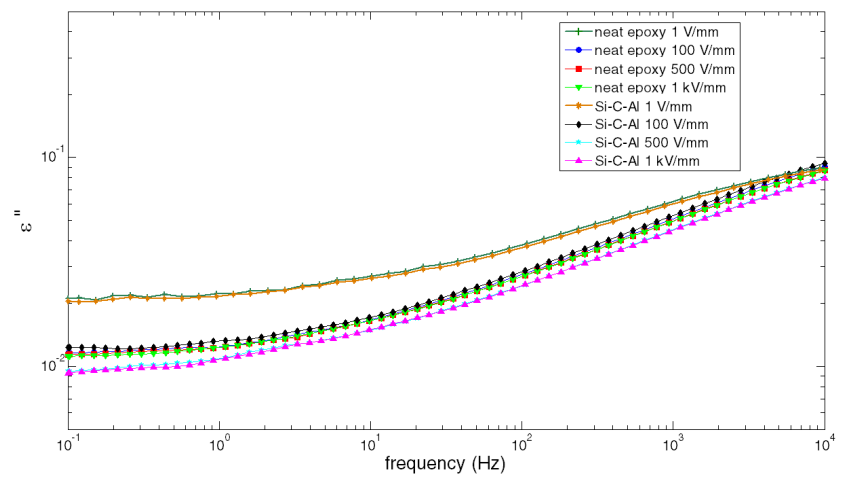

Figure 7. Imaginary permittivity under low and high electric field (from $1 \mathrm{~V} / \mathrm{mm}$ to $1 \mathrm{kV} / \mathrm{mm}$ ), for both neat and composite sample

profile through the center of the sample. The presence of free $\mathrm{C}$ was detected in the powder mix and although in small quantity, could play a very active in initiating local discharge in the epoxy composite and constitutes defects leading to breakdown.

Concerning the dielectric response; first, as shown in Figure 5 , at a constant frequency of $0.1 \mathrm{~Hz}$, both materials showed similar behavior during the 24 -h post-heat treatment at $100{ }^{\circ} \mathrm{C}$. By further analyzing the spectra in Figure 5, we can observe a slope change in the real permittivity which suggests that a regime change occurs in the physical properties of the material. In the first hours, crosslinking is completed and part of the absorbed water is removed; later in time, as the decrease becomes linear with time, the material tends to reach its stable dielectric state [8].

After the post-heat treatment, the dielectric responses as well as the AC conductivity were measured under low and high electric field, from $1 \mathrm{~V} / \mathrm{mm}$ up to $1 \mathrm{kV} / \mathrm{mm}$. The real and the imaginary permittivity are presented in Figure 6 and Figure 7. The AC conductivities are plotted in Figure 8.

Similar to the previous results, the real permittivity confirms that the two materials have similar properties, the values of the $\varepsilon^{\prime}$ being close, both at low and high applied electric fields. The measured permittivities were found to be around 4.1 and a clear separation between the obtained values cannot be made since the difference between the highest and the lowest value 


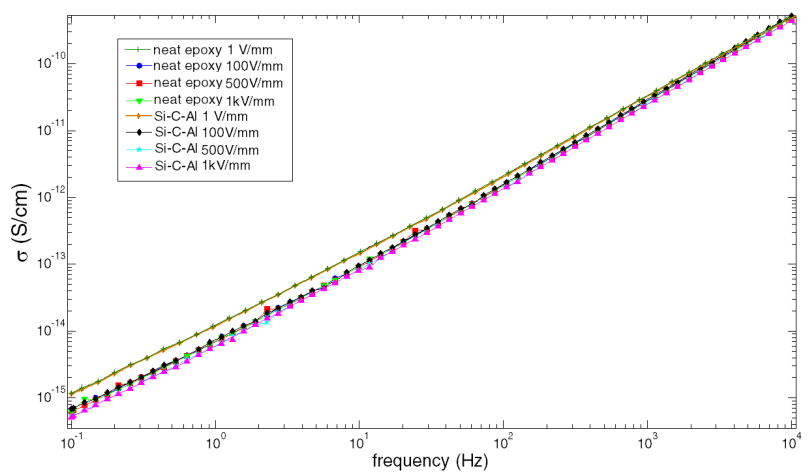

Figure 8. AC conductivity under low and high electric field (from $1 \mathrm{~V} / \mathrm{mm}$ to $1 \mathrm{kV} / \mathrm{mm}$ ), for both neat and composite sample, at $20^{\circ} \mathrm{C}$

is equal to the accepted uncertainty limit for this particular type of measurement $(\approx 0.1)$. Dielectric losses exhibited comparable results, with a slight difference for the low-voltage values which exhibit slightly higher losses for both neat and composite material. Since different low/high voltage cells were used during the two measurements, we cannot clearly differentiate the behaviour under low/high electric field. Thus, we can consider that the two materials present extremely similar properties and that the adjunct of a low percentage of micrometric fillers did not change the dielectric response.

The same conclusions apply to the results obtained for the AC conductivity, which varies between $1.7 \cdot 10^{-15} \mathrm{~S} / \mathrm{cm}$ at low frequencies up to $5 \cdot 10^{-10} \mathrm{~S} / \mathrm{cm}$ at high frequencies for both neat and composite material.

\section{CONCLUSIONS}

This work was concerned with an unusual inorganic additive. Ball milling was used to prepare a mixture of Silicon (Si), Graphite (C) and Aluminum (Al) following a heat treatment at $500{ }^{\circ} \mathrm{C}$. Efforts were devoted to characterize the resulting powder mixture. A micrometric-size micro-structure was established for the powder that showed a majority of nonconductive constituents except for the presence of free $\mathrm{C}$. Some remaining Aluminum should be also present. For these

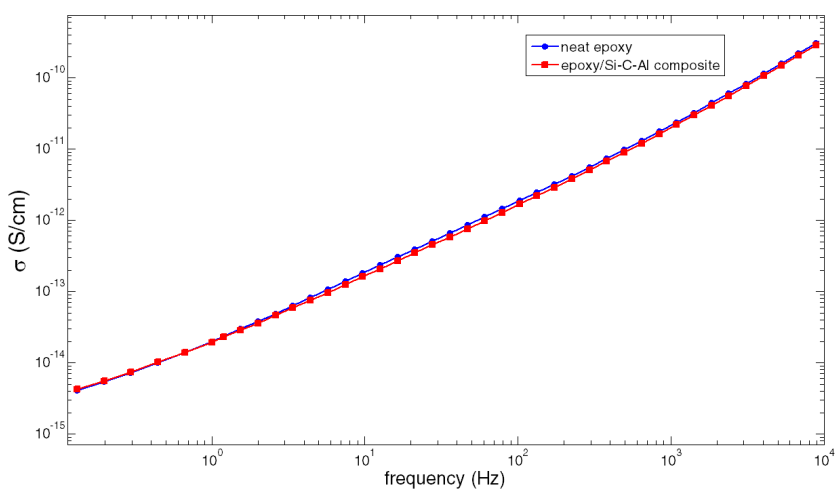

Figure 9. AC conductivity under low electric field $(1 \mathrm{~V} / \mathrm{mm})$, for both neat and composite sample, at $60{ }^{\circ} \mathrm{C}$ reasons, this preliminary study focused on a very low-content Al-Si-C, viz. $0.1 \mathrm{wt} \%$, in an epoxy compo-site.

A series of investigations were carried out to characterize the extrinsic performance of the composite as compared to that of the neat epoxy. In particular, an interesting comparison was made between low and high fields dielectric response in the frequency domain. In the present assessment, no difference was observed between the neat and composite epoxy properties except during the erosion experiment. In this case, the composite suffered from an early breakdown seemingly due to the presence of semi-conductive particles. This observation indicates that a breakdown experiment could help in confirming the counter performance of the composite.

\section{ACKNOWLEDGMENT}

Financial support from the "Nanodielectrics program" (IREQ) and the Natural Sciences and Engineering Research Council of Canada (CNSERC) are gratefully acknowledged. Karine Inaekyan from ETS, as well as Hugues Couderc and Carlo Baillargeon from IREQ are thanked for their help with the sample characterization.

\section{REFERENCES}

[1] R. Mitra, V.S. Chalapathi Rao, R. Maiti, M. Chakraborty, "Stability and response to rolling of the interfaces in cast $\mathrm{Al}-\mathrm{SiC}_{\mathrm{P}}$ and $\mathrm{Al}-\mathrm{Mg}$ alloy$\mathrm{SiC}_{\mathrm{P}}$ composites", Materials Science and Engineering A379, pp. 391400, 2004.

[2] M. Gu, Z. Mei, Y. Jin, Z. Wu, "Structure and amorphization of the oxide on the silicon carbide surface in an $\mathrm{SiC}_{\mathrm{P}} / \mathrm{Al}$ composite", Scripta Materialia, Vol. 40, no. 9, pp. 985-991, 1999.

[3] R. Warren and C-H. Anderson, "Silicon carbide fibres and their potential for use in composite materials. Part II.", Composites, Vol. 15, no. 2, 1984.

[4] A. Malchere and E. Gaffet, "Etude structurale du système ternaire $\mathrm{Al} / \mathrm{Si} / \mathrm{C}$ par mécanosynthèse" (French), "Structural study of the ternary system Al/Si/C by mecano-synthesis", Journal de Physique IV, Colloque C3, supplement of Journal de Physique III, Vol. 4, 1994.

[5] T. Heid, S. Savoie, C.Vanga, M. Fréchette, E. David, N. Freebody, A. Vaughan, "Surface resistance of epoxy/BN micro- and Meso-composites exposed to electrical discharges", Proc. IEEE Int. Conf. Solid Diel. (ICSD), pp.872,875, 2013

[6] M.F. Fréchette, E. David, H.D. Martinez and S. Savoie, "Post-heat treatment effect on the dielectric response of epoxy samples", IEEE Conf. Electr.Insul.Dielect.Phenom, pp. 705-709, 2009.

[7] H. Couderc, M. Frechette, S. Savoie, M. Reading, A.S. Vaughan, "Dielectric and thermal properties of boron nitride and Silica epoxy composites", Proc. IEEE Int. Symp. El. Insul., pp.64-68, 2012.

[8] I. Preda, J. Castellon, S. Agnel, H. Couderc, M. Fréchette, F. Gao, R. Nigmatullin, S. Thompson, A.-F. Vaessen, "Dielectric response of various partially cured epoxy nanocomposites", IEEE Trans. Diel. Electr. Insul., Vol. 20, No. 2, pp. 580-591, 2013. 